\title{
La crisis del sistema transnacional y el cambio en las relaciones internacionales de los países en desarrollo*
}

\author{
GONSIDERACIONES INTRODUCTORIAS
}

Uno de los principales aportes del pensamiento latinoamericano a la comprensión de los problemas del Tercer Mundo radica en su interpretación acerca de las relaciones entre los países desarrollados o "centrales" y en desarrollo o "periféricos".

De acuerdo con esa interpretación, el desarrollo de los países de la periferia no debía entenderse como una réplica retrasada de la evolución experimentada por los centros sino como parte de un solo proceso que produce desarrollo en los centros y subdesarrollo en la periferia. Otra hipótesis aportada por esta interpretación consiste en que, precisamente como consecuencia de la indisolubilidad de ese proceso, los estilos de desarrollo de los países periféricos dependen estrechamente de la forma que adoptan sus relaciones con los centros.

Inicialmente esas relaciones se analizaron a la luz del esquema "centro-periferia" acuñado por la cEPAL. Más adelante, dicho análisis se efectuó en función de una visión modificada de aquel esquema, que situó aquellas relaciones dentro del marco de un proceso de "transnacionalización", considerado como el rasgo dominante del sistema internacional contemporáneo. La crísis que está enfrentando el "sistema transnacional" surgiclo como consecuencia de dicho proceso podría hacer necesario replantear una vez más el estudio de aquellas relaciones.

Este trabajo parte de la hipótesis de que un conjunto de factores, entre los cuales se cuentan el desequilibrio ecológico mundial, la inseguridad en el abastecimiento de energía y de recursos naturales, y la pérdida de algunas de las ventajas relativas de que disfrutaban

* Versión modificada del trabajo presentado por los autores al seminario sobre Estilos de Desarrollo y Medio Ambiente en América Latina, organizado conjuntamente por GEPAL/PNUMA. Los conceptos expresados por los autores no representan necesariamente la posición de la institución a que ambos pertenecen. 
los países desarrollados, -en medio de un escenario mundial de inestabilidad, recesión e inflación crónicas- están provocando la crisis del sistema transnacional que se ha venido construyendo durante los últimos años. Essa crisis, en sus manifestaciones más aparentes, puede identificarse con la inflexión del ciclo expansivo que habian vivido los grandes centros industriales durante los tres decenios precedentes. Los factores anteriormente mencionados, han contribuido a crear conciencia de que existen límites al crecimiento de esos centros e incluso al de la economía mundial en su conjunto. En otras palabras, habríamos entrado un período postkeynesiano en que la preocupación por el manejo de la demanda estaría siendo desplazada por la emergencia de cuellos de botella y de precios relativamente altos en lo que se refiere a los recursos necesarios para mantener el ritmo de crecimiento de las sociedades industrializadas.

La otra hipótesis que se sustenta en este trabajo es la de que esta crisis, y la situación de incertidumbre que ésta conlleva, no sólo representa riesgos para los países en desarrollo sino que también los enfrenta con oportunidades. Esta hipótesis, por lo demás, se ajusta al carácter ambivalente de toda crisis, tal como este concepto fuera definido por don José María Medina Echeverría, cuando la describe como "cierto momento en la evolución de un sistema que ofrece suficientes manifestaciones de vacilación y trastorno como para indicar un estado de transición, que no excluye tanto su recuperación y fortalecimiento, como su definitiva descomposición y ruina".

En efecto, la conciencia de que existen límites al crecimiento económico mundial ha permitido apreciar más claramente lo que significa vivir en "una sola tierra", y ha agudizado la percepción de la inter. dependencia que existe entre todos los pueblos del mundo. Durante los últimos años, esa relación de interdependencia se ha hecho sentir también en el plano de las relaciones entre los países en desarrollo y los desarrollados, lo que ha movido a unos y a otros a buscar áreas de intereses mutuos. En efecto, la estabilidad y el funcionamiento ordenado de los países industrializados depende cada vez más del progreso que alcancen los países de la periferia. Del mismo modo, históricamente el desarrollo de estos últimos ha ido asociado a una integración creciente en la economía internacional.

Sin embargo, el hecho de que las relaciones entre ambos grupos de países se hayan tornado más interdependientes que en el pasado . no significa en modo alguno que hayan dejado de ser asimétricas. Los países industrializados continúan desempeñando un papel central 
en el sistema y la nueva relación que se postula es una relación de interdependencia entre desiguales. Lo anterior tampoco significa que la búsqueda de una mutualidad de intereses entre ambos grupos de países implica que sus tradicionales y profundos conflictos hayan quedado superados. En el fondo se trata de una mutualidad de intereses potencial, cuya materialización en acuerdos y acciones concretos requerirá de arduas negociaciones, en que muchas veces los intereses en conflicto predominarán sobre los comunes y en que, como más adelante se señala, el predominio de estos últimos dependerá de que los países centrales acepten la introducción de reformas estructurales a nivel global que tornen menos sesgado en su favor el funcionamiento del sistema internacional. En todo caso, lo que en este trabajo se sugiere es que los cambios que están teniendo lugar en las relaciones centro-periferia, como consecuencia de la crisis del sistema transnacional, no sólo entraña riesgos para esta última sino que también le ofrece oportunidades. De ser ello así, las alternativas que enfrentarian estos países en el diseño de sus estrategias externas no deberían consistir solamente en incorporarse en forma indiscriminadamente o sustraerse de un modo radical a las nuevas formas de transnacionalización que están teniendo lugar en el sistema internacional, sino que incluirían la posibilidad de ensayar modalidades de participación selectiva en el sistema, basadas en un cuidadoso balance de los costos y beneficios que podrían derivarse de las diversas formas de insersión posibles, particularmente desde el punto de vista del impacto de esa insersión externa sobre sus respectivos estilos de desarrollo. Al final de este trabajo sugeriremos las opciones básicas que actualmente enfrentan los países en desarrollo a este respecto.

\section{LA INGIDENCIA DE NUEYOS FACTORES EN LA EVOLUGION DE LAS} RELAGIONES GENTRO-PERIFERIA

La teoría convencional del desarrollo y de la cooperación internacional.

Durante la segunda postguerra se acentúa el interés de la comunidad. internacional por los países subdesarrollados. Varias regiones en desarrollo habían contribuido al esfuerzo bélico abasteciendo de materias primas y recursos naturales a los contendientes quienes, de esta manera, adquirieron una mayor familiaridad $y$ establecieron nuevas vinculaciones económicas con ellas. Por otra parte, el hecho. 
de que el teatro de la guerra se extendiera a regiones muy remotas provocó cambios políticos en las sociedades respectivas y las incorporó en forma forzosa a la política internacional, pavimentando el camino para el proceso de descolonización que se desencadenaría muy aceleradamente algunos años más tarde. Sin embargo, en un comienzo ese interés se desarrolló lentamente, debido a la escasa representación que tuvieron los países en desarrollo en la etapa fundacional de las Naciones Unidas y a la prioridad asignada por los Estados Unidos a la reconstrucción de los países devastados por la guerra, simultáneamente con su preocupación por la restauración del sistema capitalista internacional, profundamente afectado por varias décadas de crisis y conflagraciones bélicas y por la consoliclación del mundo socialista. Con todo, a lo targo de los años 50 continúa aumentando el interés de la comunidad internacional por los países en desarrollo. En este proceso surgen una serie de teorías sobre la naturaleza del desarrollo y las estrategias más adecuadas para promoverlo, incluyendo en forma importante el papel de la cooperación internacional en la formulación de estas estrategias.

EI común denominador de todas estas teorías es su tendencia a asimilar "desarrollo" con "modernización". El desarrollo era concebido como un proceso unilineal, que pasa necesariamente por etapas preestablecidas, siguiendo un camino que deben recorrer todos los países de un modo similar. La brecha entre el desarrollo y el subdesarrollo se debe a que algunos países lo recorrieron en una período más temprano, particularmente aquellos que llevaron a cabo la revolución industrial, mientras que otros se encuentran en las primeras etapas de esa ardua jornada o ni siquiera la han iniciado. Las ciencias sociales de esa época confluyen en señalar que el motor del desarrollo no radica solamente en la acumulación de capital, sino en la modernización global de las respectivas sociedades, un proceso que hace posible el empleo del capital y en donde éste a su vez juega un papel muy importante. Son muchos los testimonios acerca de esta convergencia.

Unos prefieren centrar sus estudios sobre el desarrollo, y las condiciones para lograrlo, en la estructura de la personalidad. Desde este punto de vista, la modernización se alcanzaría pasando de la persona. lidad orientada por la tradición que predomina en sociedades rurales y comunitarias (edad media) a otra orientada desde adentro, que es la que se encuentra en la base de sociedades burguesas en pleno proceso expansivo (renacimiento), y finalmente a una personalidad orientada hacia afuera típica de una sociedad de servicios con un 
alto nivel de consumo como la que presentan los países desarrollados en la actualidad (Riesman, 1951). Para otros, una sociedad es moderna cuando sus miembros han conseguido internalizar profundamente la "orientación hacia el logro", contrapuesta a la conformidad con el status establecido (McClelland, 1961). Otros, en fin; desarrollan la comparación entre la personalidad autoritaria y la personalidad creativa, viendo en la primera el baluarte de las sociedades tradicionales y en la segunda la fuente más dinámica de modernización y crecimiento económico (Hagen, 1962).

Los numerosos ensayos efectuados alrededor de la misma época para caracterizar diversos conjuntos de valores sociales alternativos, más o menos favorables a la modernización y el crecimiento, constituyen variaciones y aportes sobre el mismo tema. Como es sabido, una de las contribuciones más importantes e influyentes a este esfuerzo es la que propone un conjunto de pautas alternativas de comportamiento social, las primeras de las cuales aseguran la conservación de una sociedad tradicional mientras que las otras conducirían a una sociedad moderna (Parsons y Schils, 1951), en que al decir de un exponente de este enfoque en Latinoamérica, la llamada conducta "prescriptiva" es gradualmente reemplazada por diversas formas de acción "electiva" (Germani, 1962).

El mismo enfoque, trasladado al plano económico, llevó a señalar las etapas por las que debería atravesar el proceso de desarrollo económico, poniendo énfasis en las precondiciones necesarias para iniciar el período de "despegue", caracterizado como un "intervalo en que los antiguos escollos y resistencias a un crecimiento sostenido son finalmente superados" o como un "intervalo decisivo en la historia de una sociedad en que el crecimiento llega a ser una condición normal". (Rostow, 1960). Especial importancia se asigna, entre aquellas precondiciones, a los progresos alcanzados en materia de energía, transporte, comunicaciones, educación, salud y demás competentes de la llamada infraestructura económica y social, así como a la expansión de los bancos y las inversiones, y a la emergencia de una clase empresarial de orientación moderna o comercial. Una variante de este enfoque que identifica el motor del desarrollo con la modernización y la expansión del capital social, considerado como expresión y medida de este último proceso, se encuentra en la teoría del big push propuesta en esa misma época (Rosenstein Rodan, 1961). En todas estas. propuestas el desarrollo se identifica con la modernización y ésta, en buena medida, con la construcción de nuevas plantas gene- 
radoràs de energía eléctrica, vías férreas, puertos, carreteras, represas y otras inversiones llamadas a sentar las bases de la industrialización y el remozamiento de la agricultura.

En este proceso la cooperación internacional ocupaba un papel muy destacado. Apenas se planteaba la posibilidad de que la causa del subdesarrollo de los países periféricos radicara, precisamente, en sus relaciones históricas de tipo centro-periferia con los países industrializados. Se presumía la existencia de una suerte de "armonía natural de intereses" entre ambos grupos de países. De acuerdo con esta concepción; el desarrollo de los países periféricos habría de ser inducido en buena medida por el crecimiento económico del mundo industrializado, con la ayudia de los programas de cooperación externa impulsados por estos. Se admitía, por cierto, que las relaciones entre amboś grupos de países eran marcadamente asimétricas, pero se atribiría esta situación al hecho de que los distintos países se encontraban en diferentes "etapas de crecimiento económico". Como se ha dicho, el desarrollo se concebía como un proceso unilineal, y se suponía que todos los países debían recorrer un mismo camino, dividido en ciertas etapas. En esta jornada, los países que habían partido primero tenían ciertas ventajas sobre los recién llegados, lo que planteaba la necesidad de la cooperación internacional. Con la ayuda de esta última, y del trickle down effect causado por la creciente prosperidad de los países indústrializados, estas diferenciaciones tenderían a superarse, conforme avanzaran el desarrollo, la modernización y la integración de los países retrasados en la economía internacional.

Así como las estrategias de desarrollo basadas en tales prescripciones no condujeron a los resultados esperados, en el plano interno, en el plano internacional el período que se extiende hasta los años 60 concluyó con un acendrado sentimiento de "desilusión frente a la ayuda"**. No es de extrañar, entonces, la autocrítica con que inicia su análisis uno de los más prestigiosos informes preparados al fin de ese período en torno a los resultados de la cooperación internaciona: "Los países donantes y.receptores, por igual, tendieron a concebir la modernización y el desarrollo de los países de bajos ingresos cómo un intento de reproducir la revolución industrial en

* Lo atestiguan las conclusiones de numerosos informes encargados al concluir el decenio de los años 60 con el objeto de evaluar la eficacia de la cooperación internacional, en distintos ámbitos, como los informes preparados por los señores Pearson, Peterson, Prebisch y Rockefeller Para una apreciación crítica de esos informes ver Jaguaribe, 1976. 
un tiempo muy breve. Prestaron una atención desmesurada a la ejecución de proyectos específicos de inversión, y relativamente muy poca a las causas y resultados del subdesarrollo" (Pearson, 1969, pág. 5).

\section{El esquema de análisis centro-periferia.}

El enfoque anterior tenía, entre otros, el defecto fundamental de ser profundamente ahistórico. Pasaba por alto los antecedentes y las características estructurales que moldearon durante un largo proceso histórico las relaciones entre países en desarrollo y desarrollados. Suponía que el desarrollo constituye un proceso que se da ind'ependientemente en distintos lugares y momentos del tiempo y que incluso consiste en reproducir, bajo distintas circunstancias, un modelo previo. La CEPAL cuestionó desde el inicio de sus actividades, alrededor de los años 50, estas presunciones, Para ella, el subdesarrollo no consiste simplemente en la falta de crecimiento sino, por el contrario, constituye la manera misma de desarrollarse de las economías periféricas. Este análisis, desde un principio, contuvo los elementos que andando el tiempo llevarían a plantear la existencia de un sistema económico que genera, a la vez, desarrollo en los centros y subdesarrollo en la periferia. De acuerdo con la explicación cepalina, este fenómeno se debía a la forma extremadamente desigual en que el progreso técnico se propagaba a través de la economía mundial. En los centros, que son los autores de dicho progreso, los métodos de producción que éste genera se difunden en la totalidad del sistema productivo en un periodo relativamente breve. En la periferia, que parte de una situación inicial de retraso, las nuevas técnicas penetran lentamente y sólo se implanta en las primeras etapas del desarrollo capitalista en los sectores exportadores (por lo general de bienes primarios), los que deben coexistir con sectores rezagados desde el punto de vista de la absorción de nuevas técnicas y del nivel de productividad que ellas generan (cepal, 1949; Prebisch, 1952; Pinto, 1965).

Lo anterior determinaba que el centro y la periferia presentaran, entre otras, tres diferencias fundamentales. La primera se refería al dinamismo del crecimiento en uno y otro grupo de países y consistía en que, siendo el progreso técnico más acelerado en los centros que en la periferia, la productividad -y por consiguiente los ingresos medios-crecían más rápidamente en los primeros, por lo cual tendfa a ensancharse la brecha existente entre ambos polos. La segunda consistía en que el desarrollo de la periferia tendía a concentrarse 
unilateralmente en el sector primario exportador, en tanto que el aumento y lá diversificación que moderadamente experimentaba la demanda por bienes y servicios como consecuencia de este desarrollo, se satisfacía en gran medida con importaciones, impidiendo la creación y expansión de la industria manufacturera. La tercera tenía relación con la heterogeneidad del desarrollo de la periferia, en el sentido de que en ella coexistían sectores de alta productividad -generalmente el sector exportador-con actividades en las cuales la productividad del trabajo era muy inferior a la de actividades similares en los centros.

Estas diferencias dieron lugar a una división internacional del trabajo en que a la periferia correspondía el papel de producir alimentos y materias primas para los grandes centros industriales, importando desde estos los bienes manufacturados necesarios para atender sus necesidades de consumo, así como también los bienes de capital requeridos para proseguir su proceso de desarrollo. Dicho esquema suponía que. la demanda por productos primarios en los centros iba a crecer al mismo ritmo que el aumento del ingreso y que, además, los beneficios derivados del incremento de la productividad en sus actividades industriales se transferirían hacia la periferia en forma de una baja correlativa de los precios. Ninguno de esos supuestos se verificó en la práctica. De hecho, la demanda por alimentos y materias primas representó una fracción declinante del ingreso en los centros, y los productores de los paises industrializados - tanto empresarios como trabajadores- tendieron a retener las ganancias generadas por el progreso técnico y a traducirlas en un aumento sostenido de sus ingresos.

El mecanismo que hizo posible esa retención por parte de los centros es la relación de precios del intercambio, la que ha tendido en el largo plazo a evolucionar en contra de los productos primarios, con lo cual los países de la periferia han estado transfiriendo hacia los centros una parte de Ios beneficios derivados del incremento de la productividad en sus sectores primarios exportadores ${ }^{1}$. A esto se agrega que Ia demanda por productos primarios tendió a crecer en

${ }^{1} \mathrm{Lo}$ que ha ocurrido recientemente con los palses exportadores de petróleo ilustra, a contrario sensu, la significación de este fenómeno. Supóngase que en lugar de precios reales de exportación bajos y declinante, y escasa tributación a. las compañías extranjeras, los países de la oPEP hubieran podido captar parte sustancial del excedente transferido al exterior descle la década de 1920, e iniciado desde entonces un proceso de acumulación similar al de la última década. Su stock de 
forma irregular y lenta en los centros mientras que la demanda por manufacturas y bienes de capital se expandía continuamente en la: periferia. De allí la tendencia secular al deterioro de los términos del intercambio, en virtud de la cual el poder de compra de bienes industriales derivada de la exportación de una unidad de bienes primarios se reduce con el transcurso del tiempo, y los ingresos generados por estas actividades crecen lentamente.

Otros factores incidieron también en esta tendencia. Entre ellos se cuenta la sustitución generalizada de productos naturales por bienes sintéticos; la declinante participación de los insumos primarios en el valor de los productos finales; las políticas proteccionistas aplicadas por los países industrializados en contra del acceso de los productos básicos a sus mercados; el bajo grado de elasticidad-precio de los productos exportados por la periferia, que determina que una declinación de sus exportaciones y una consiguiente caída de sus. precios no se traduzca en mayores importaciones de esos mismos productos por parte de los centros, los cuales simplemente destinan una menor proporción de sus ingresos a la adquisición de dichos bienes, $y$ en general el hecho de que los productos primarios representen una proporción decreciente de la demanda global de los centros.

La industrialización de los países de la periferia emergía a Ia luz de este análisis como el único camino que, al cambiar la especialización de esos países en la división internacional del trabajo, les permitiría mejorar los términos de su intercambio y retener una cuota mayor de los frutos del progreso técnico. La drástica reducción experimentada por el valor de sus exportaciones como consecuencia de la crisis de los años 1930, y las dificultades adicionales para importar provocadas por la guerra, suministraron nuevos incentivos para adoptar políticas de protección y estímulo a la creación de una industria que náturalmente durante una primera etapa se orientó hacia la sustitución de importaciones.

El esquema centro-periferia, al iluminar la estructura de las relar ciones económicas entre los países industrializados y los países en desarrollo, puso de manifiesto la estrecha vinculación existente entre

capital fijo sería ahora cuatro o cinco veces mayor, su proceso de desarrollo habria sido más gradual y armónico, y en general, serian hoy países bien diferentes a Io que son actualmente. $\mathrm{Y}$ también serian diferentes las empresas y países que se beneficiaron durante medio siglo con esa transferencia de excedenteș. 
el desarrollo de los centros y el subdesarrollo de la periferia, dando lugar a una fecunda línea de análisis en relación con estos temas.

Es natural que algunas de sus tesis hayan sido controvertidas y que la explicación de algunos puntos haya quedado pendiente. Así por ejemplo, en primer lugar, la tendencia al deterioro de los términos del intercambio más de una vez ha sido cuestionada a la luz de la evidencia empírica (Ellsworth, 1956; Harberler, 1969, y Flanders, 1964), o ha sido considerada válida no tanto en términos de la evolución real de los precios de los productos primarios, sino de la que esperaban los países en desarrollo (Fishlow, 1978). En segundo Iugar, no se introdujeron sino bastante después en ese esquema factores claves para el análisis de las relaciones económicas internacionales entre ambos grupos de países, como la naturaleza de sus nexos financieros, las modalidades que adopta el proceso de transferencia de tecnología y el papel de las empresas transnacionales. Por último, no se llegó a comprender suficientemente en un comienzo que la influencia ejercida por los centros sobre la evolución económica de la periferia no es puramente exógena, sino endógena a esta última, en la medida en que en virtud de la progresiva formación de una economía transnacional de alcance global los países periféricos - o algunos segmentos de èllos- pasan a formar parte de la frontera económica de los centros.

Por otra parte, las estrategias de industrialización por sustitución de importaciones no alteraron, en lo sustancial, la especialización de esos países en la división internacional del trabajo y, sobre todo, no los encauzaron por la senda de un crecimiento más autónomo o autosostenido ni redujeron sensiblemente su tradicional dependencia externa.

Estas consideraciones llevaron a plantear el tema de las relaciones entre países desarrollados y países en desarrollo dentro de un contexto más amplio.

\section{El análisis del proceso de transnacionalización.}

"El enfoque centro-periferia ha sido muy útil para explicar los procesos históricos del desarrollo capitalista en la periferia en función de las características de los centros correspondientes y de sus etapas de expansión y crisis... Así, por ejemplo, se reconoce que la difusión de la revolución industrial y la expansión imperialista de los países centrales durante la última parte del siglo xIx, es el elemento que más ha contribuido a convertir los países periféricos en exportadores 
especializados de productos primarios. Por otra parte, se acepta que el período de crisis por el que atravesó el capitalismo desde la primera guerra mundial hasta los años 40 fue un factor determinante del proceso de industrialización de muchos países subdesarrollados en esa época. Sin embargo, salvo en el sentido restringido de la importancia que revisten los mercados externos de productos básicos, tecnología y capital, y del crecimiento de las empresas transnacionales en la postguerra, que se ha destacado en la literatura sobre la dependencia, el análisis del proceso de desarrollo de los países periféricos en las últimas dos décadas se lleva frecuentemente a cabo como si aquel marco capitalista global hubiese dejado de existir, hubiese permanecido esencialmente invariable o careciese de importancia" (Sunkel y Fuenzalida, 1978).

El reconocimiento de la influencia que aquel marco capitalista global ejerce sobre la totalidad de los aspectos del proceso de desatrollo de los países de la periferia condujo a profundizar en el análisis de la formación de una economía transnacional en que los países centrales y los países periféricos no se encuentran vinculados sólo por relaciones externas, que fundamentalmente tienen lugar en los mercados de bienes y factores, sino que forman parte de un mismo sistema cuyos rasgos permea profundamente la estructura política, éconómica, social y cultural de los segundos (Sunkel 1971; Sunkel y Fuenzalida, 1978; Keohane y Nye, 1970 y 1977 y otros) .

El análisis centro-periferia había prestado atención preferente a las actividades de exportación en que se especializaban los países en desarrollo (fundamentalmente primarias), lo que podría haber llevado a pensar que éstas constituyen su única o principal forma de vinculación con los países desarrollados, así como a la conclusión de que la industrialización de los países de la periferia habría de traer consigo un proceso acumulativo de erecimiento autosostenido. Ello habría equivalido a repetir en la periferia la revolución industrial que llevara a cabo Europa en los siglos xvIII y xrx. Dicho análisis no subrayaba suficientemente el hecho de que los países europeos llevaron a cabo esa transformación en forma autónoma, mientras que el crecimiento de los países de la periferia se verifica actualmente de conformidad con estilos de desarrollo sustancialmente determinados por las tendencias del sistema transnacional de que forman parte, cuyo centro dinámico radica en los países industriales.

De hecho, el desarrollo de los países latinoamericanos -que inspiró buena parte de estas reflexiones- presentó rasgos bien diferentes a Ios 
que caracterizaron el crecimiento y la modernización de los países hoy industrializados, precisamente como consecuencia de que aquella experiencia se verificó en una etapa de organización transnacional de la economía mundial y de que, por consiguiente, el marcó dentro del cual fue necesario concebir el desarrollo nacional era el-nuevo sistema global que entonces emergía. En la práctica, el proceso de industrialización latinoamericano sería incomprensible si se lo abstrayera del cuadro de vinculaciones, condicionantes y presiones externas que tan decisivamente han influido sobre su evolución y sus características.

En efecto, dado el nivel incipiente de que partieron cuando iniciaron su industrialización, los países latinoamericanos se vieron abocados a la necesidad de expandir dramáticamente su disponibilidad de recursos humanos calificados, capacidad empresarial, maquinarias y equipos, conocimientos tecnológicos, recursos financieros, instituciones de crédito, publicidad y comercialización, y otros elementos indispensables para llevar a cabo esa tarea. Por lo demás, a medida. que el desarrollo industrial de los países pasa de sus fases más elementales, con respecto a las cuales ya existía una cierta capacidad instalada y experiencia, a etapas más complejas, la necesidad de esos elementos se hace cada vez más crítica. De allí que el proceso de industrialización se haya apoyado sustancial y crecientemente en la incorporación de elementos externos. De allí también que la capacidad para absorber esos flujos de recursos productivos externos, y la forma de hacerlo, ha sido una de las variables que ha incidido más decisivamente en los resultados de la industrialización en los diversos países latinoamericanos, en cuanto a su influencia sobre el ritmo de crecimiento de la economía, los niveles de ocupación, la distribución del ingreso, la estructura del producto, la diversificación de las exportaciones, las vinculaciones financieras externas, la situación de balanza de pagos y las características que adoptó en cada caso la propiedad de dichos recursos productivos.

Lo anterior pone de manifiesto que si bien los países latinoame. ricanos impulsaron su industrialización a través de políticas delibe. radas, y encontraron un estímulo adicional en la desarticuláción que sufrieran las relaciones económicas internacionales como consecuencia de la crisis de los años 30 y de la guerra, dicho proceso no se llevó a cabo en forma aislada e incluso hasta cierto punto autónoma, como a veces se ha señalado, sino que logró implantarse gracias al establecimiento de nuevas y profundas vinculaciones con las economías extranjeras. Pone de manifiesto también que la industrialización no atenuó 
sino que sólo alteró la dependencia externa de las economías latinoamericanas, las cuales fueron sustituyendo sus importaciones de bienes de consumo por las de aquellos bienes de capital e insumos requeridos para proseguir su proceso de industrialización, abriendo paso así a una nueva etapa en la inserción de las economías latinoamericanas en un sistema económico internacional profundamente transformado.

Esa transformación respondía en buena medida a la evolución de la economía mundial desde una etapa basada en la internacionalización del comercio y la producción primaria a otra caracterizada por la internacionalización de la producción manufacturera y de los ser. vicios. Uno de los principales agentes de esta transición fue la corporación transnacional que comenzó a expandirse durante ese período. $Y a$ a fines de los años 60 el valor de la producción de las subsidiarias de empresas transnacionales basadas en los países de la ofGD bordeaba el valor representado por el comercio internacional. Su gravitación fue alentada por la acelerada tendencia hacia la conglomeración de actividades bajo una misma firma, tanto vertical como horizontal ya sea mediante el control de las actividades correspondientes a toda la cadena del ciclo productivo o de actividades distribuidas a lo largo de una amplia gama de ramas industriales. En las 14.000 fusiones entre firmas verificadas durante el período de 1953-1968, el $35 \%$ de todos los activos fusionados fueron adquiridos por 100 firmas, las cuales han incrementado notablemente su participación en este tipo de operaciones a partir de este último año. Del mismo modo, las 500 firmas industriales más grandes de acuerdo con la revista Fortune aumentaron su participación en los beneficios globales del sector industrial de un $40 \%$ a más del $70 \%$, entre 1955 y 1970 (Müller, 1977-1978). Como declarara un distinguido analista de este proceso hace diez años, "el estado, considerado como una unidad económica, está prácticamente superado" (Kindleberger, 1969). La misma observación hacía el director de la IBM en Europa, al estimar que "las estructuras políticas del mundo se encuentran completamente obso. letas; no han cambiado en por lo menos 100 años y están, lamentablemente, fuera de tono con el progreso tecnológico" (Jacques Maison. rouge, citado en Müller, 1974). En todo caso, cualquiera que sea el futuro del estado nacional a largo plazo, la economía transnacional en formación está promoviendo una creciente interpenetración entre las economías nacionales y exige una coordinación cada vez mayor entre las políticas económicas de los distintos países, incluyendo tanto a. Ios países desarrollados como a los menos clesarrollados. La consoli- 
dación de una especie de comunidad transnacional reclutada con base en los conocimientos técnicos, la capacidad ejecutiva y la visión global de sus miembros, y basada en una especie de cultura igualmente transnacional constituida por un conjunto de valores, objetivos, calificaciones profesionales, patrones de consumo, símbolos de status y formas de vida semejantes, es condición necesaria para la consolidación de este sistema. La existencia y ulterior expansión de un complejo marco de organizaciones internacionales contribuye de diversas maneras al fortalecimiento del proceso.

La acelerada integración de los países en desarrollo a este sistema refuerza la coexistencia, dentro de ellos, de sectores "transnacionalizados" con sectores marginados. En esto juegan un papel muy importante los núcleos transnacionales existentes al interior de esos países, cuyo objetivo es reproducir localmente las condiciones de vida, las estructuras productivas y las instituciones requeridas para el florecimiento de unas y otras, a imagen y semejanza de los demás grupos transnacionales del sistema. Estos grupos locales, y sus intereses, ejercen una influencia decisiva sobre la formulación de las estrategias nacionales, a las cuales se exige que sean funcionales con la creciente integración de estos países en el sistema transnacional en formación. La necesidad de adecuar esas estrategias a las exigencias de dicho sistema comienza a determinar en forma creciente los estilos de desarrollo de los países de la periferia.

No obstante estar basado en la percepción de la existencia de un sistema económico global, en que se van integrando cada vez más estrechamente los centros y la periferia, este análisis no excluye, sino que por el contrario supone, un alto grado de asimetría entre los diversos componentes del sistema -así como también al interior de los países periféricos que se integran al mismo- $y$, por lo tanto, de dependencia y de conflicto.

E1 extraordinario período de expansión por el que atravesaron los grandes centros industriales durante los dos decenios anteriores constituyó, sin duda, el telón de fondo que hizo posible la formación de este sistema $y$, muy particularmente, la progresiva integración de los países en desarrollo en la economía internacional. La marcada declinación experimentada por el ciclo expansivo de los centros durante el decenio de Ios años 70 (GEPAL, 1979), con su secuela de inestabilidad, recesión e inflación crónicas, no pudo alterar ya la dirección central de ese proceso, pero modifícó sus condiciones. Los rasgos anteriormente señalados, determinados en buena medida por la percepción 
de límites al crecimiento de los centros, al abatir el ritmo de desarrollo de los mismos y acentuar su vulnerabilidad externa, fortalecieron las relaciones de interdependencia entre todos los países del mundo. De esta manera la "interdependencia" dejó de ser una realidad circunscrita a los países industrializados, cuyas relaciones con los países en desarrollo eran concebidas bajo el concepto de "cooperación", y se extendió también a las relaciones entre ambos grupos de países.

El sistema transnacional y el avance de la interdependencia.

En efecto, el período que se inicia después de la segunda guerra mundial será recordado por la rápida y sostenida expansión que experimentara la economía internacional y, muy particularmente, los grandes centros industriales. Como se ha dicho, fue precisamente esa expansión sin precedentes la que lubricó los canales a través de los cuales se desarrolló el proceso de transnacionalización de la economía mundial, y facilitó la integración de los países en desarrollo. Sin embargo, andando el tiempo, fueron poniéndose de manifiesto los costos, las contradicciones y los efectos indeseables del proceso. Los años 70 se caracterizan por la inflexión del ciclo expansivo de los centros. Este fenómeno arrastra a la economía mundial en su conjunto, caracterizada desde entonces por una aguda inestabilidad, por la inseguridad del abastecimiento de energía y otras materias primas, y por tendencias inflacionarias y recesivas crónicas. No es de extrañar, entonces, que a lo largo del presente decenio no haya cesado de profundizarse la conciencia de que el crecimiento económico tiene ciertos límites. El primer informe publicado bajo los aupicios del Club de Roma sobre esta problemática (Meadows, et al., 1972), contribuyó a iniciar un debate que generó una pluralidad de posiciones sobre esta materia en el plano teórico (The Ecologist, 1972; Vard, 1973; Mesarovic y Pestel, 1974; Herrera, 1976; Vishan, 1977; Wilson, 1977), mientras que las acciones emprendidas por la OPEP en 1973 dieron la señal de alarma en el plano práctico.

Esta toma de conciencia responde al surgimiento de un nuevo escenario, cuyo rasgo principal tal vez radica en las tendencias recesivas observables en los centros, las que entre otros factores están relacionadas con la elevación de los costos productivos y la pérdida de capacidad competitiva en un número creciente de sus. ramas indus. 
triales. La tendencia de los salarios a asimilarse a aquellos que sé pagan en las ramas de más alta productividad, los requerimientos de defensa y seguridad social y la consiguiente elevación del gasto público, la saturación de la demanda por bienes durables, y la declinación del ritmo de las innovaciones tecnológicas, junto con la necesidad de afrontar costos ambientales cada vez mayores, dan Iugar a tendencias a la caída de las tasas de capitalización y de ganancia en los grandes centros industriales, a la reorientación de las inversiones hacia otras áreas geográficas, a la progresiva desaparición de la mediana y pequeña empresa tradicional, a déficits crónicos en los sistemas de transporte o infraestructura urbana y a otros fenómenos conexos que elevan los costos de operación y reducen la productividad de sus economías. Ĺa elevación general de los costos de dichos sistemas productivos explica que aquellas tendencias recesivas hayan estado acompañadas, en forma heterodoja, de sostenidas tendencias inflacionarias. El renacimiento y la extraordinaria fluidez de los mercados financieros internacionales, no sujetos a la regulación de autoridad alguna, y su interconexión creciente, contribuyó a acelerar la transmisión internacional de las perturbaciones económicas $y$, muy en particular, de la inflación. El mismo efecto ha tenido la incertidumbre en materia de abastecimiento de recursos naturales e insumos industriales. Todo ello ha creado una prolongada situación de inestabilidad internacional que a su vez contribuye a fortalecer las tendencias inflacionarias y recesivas anteriormente señaladas.

Estas tendencias, en el fondo, son expresión de la nueva forma de organización transnacional adoptada por la economía internacional. La teoría macroeconómica convencional está fundada sobre ciertos supuestos acerca del comportamiento de las empresas en la economía que han dejado de ser válidos. En primer lugar, se presume que las firmas venden sus mercaderías en mercados relativamente perfectos, que aseguran un comportamiento flexible de los precios frente a las variaciones de la oferta o de la demanda. Suponía, en segundo Iugar, que todas las empresas se comportan en forma parecida, esto es, que las diferencias nacionales en cuanto a la organización de las empresas, así como también en cuanto a su tamaño y ámbito de acción, no incide en su comportamiento. Una tercera suposición consiste en que las operaciones de las diversas empresas son independientes y no están influidas por las actividades de otras empresas ubicadas en distintos puntos de la misma cadena productiva o en otras ramas industriales. Por último, esa teoría suponía que las decisiones encami- 
nadas a fijar los precios dentro de una empresa están motivadas exclusivamente por el deseo de maximizar sus ganancias a corto plazo, y que estas ganancias se derivan sustancialmente de las actividades de una sola empresa.

La poderosa tendencia hacia la conglomeración industrial, anteriormente mencionada, ha erosionado completamente la validez de estas suposiciones. Gomo consecuencia de lo anterior, el mercado ha dejado de funcionar para muchos efectos prácticos, y las firmas tienden a comportarse en función de una programación global encaminada a maximizar sus beneficios de largo plazo al interior del conglomerado, que abarca una gran variedad de actividades vertical u horizontalmente integradas, distribuidas en diversas naciones. Como se observara hace bastante tiempo, ello torna más rígida las correspondientes decisiones, toda vez que las inversiones involucradas en ellas resultan más cuantiosas y más prolongado el lapso de tiempo requerido para implementarlas (Galbraith, 1967). Al mismo tiempo el hecho de que la maximización de las utilidades de la empresa se busque en el plano global y con relación al conglomerado en su conjunto, así como también de que las preferencias en materia de localización de sus diversas actividades industriales se resuelvan sobre la base del mercado internacional, ha inducido a las corporaciones transnacionales a transferir entre sus subsidiarias bienes intermedios y de capital, recursos financieros, tecnología, información y personal. a través de las fronteras nacionales, reemplazando los mecanismos del mercado y determinando con amplia libertad los precios, costos, tasas de interés $y$, en general, el valor de sus diversas transacciones, a través de una variedad de prácticas encaminadas a la fijación de los correspondientes precios de transferencia. En suma, dichas empresas tienden a independizarse del funcionamiento del mercado como mecanismo útil para relacionar las distintas unidades productivas y determinar los precios, fijando estos últimos en forma centralizada, al colocar las distintas unidades dentro de una misma organización y bajo el mando de una sola estructura de decisiones (Sunkel y Fuenzalida, 1978).

El impacto de estas tendencias sobre el costo de operación de los sistemas productivos en los grandes centros industriales se ve agravado por el surgimiento de una serie de problemas globales cuyo adecuado manejo y solución requiere asumir costos adicionales. Entre ellos se cuentan los requerimieritos planteados en materia de producción, almacenamiento y distribución de alimentos, en una situación en que 
la quinta parte de la población mundial sufre hambre y desnutrición, situación que además tiende a agravarse debido a que en muchos países en desarrollo la población crece más rápidamente que la disponibilidad de alimentos. Se incluye además, y con caracteres a veces dramáticos, la incertidumbre y los mayores costos vinculados con el abastecimiento de energia y otras materias primas industriales. Deben contabilizarse, asimismo, los problemas planteados por la excesiva concentración del crecimiento industrial registrado durante las últimas décadas. Similares problemas plantea la contaminación ambiental generada fundamentalmente por el alto grado de concentración de la población urbana y de las actividades económicas a que se hacía referencia más arriba.

El hecho es que comenzó a reconocerse de este modo que el ritmo y el grado de concentración del crecimiento en los centros había tenido lugar a expensas del medio ambiente, la dotación de recursos naturales y la capacidad de sustentar económicamente ciertas actividades productivas. Comenzó a percibirse, por lo tanto, el peligro que podría entrañar un crecimiento económico desmedido o incontrolado, desde el punto de vista del mantenimiento o la ruptura del delicado equilibrio ecológico en que se basa la vida de la humanidad sobre la tierra, entendiendo este equilibrio en un sentido amplio, que incluye las relaciones con el medio físico, social y cultural del hombre.

Gomo ya se ha anticipado, el malestar prevaleciente en las economías de los países industrializados, junto con el surgimiento de problemas globales como los anteriormente señalados, han traído aparejada una profundización de las relaciones de interdependencia entre todos los pueblos del mundo. Este proceso se expresa en el hecho de que cada vez resulte más difícil aislar unai sociedad nacional con respecto a las tendencias y acontecimientos que tienen lugar en el interior de otras sociedades. Se expresa, en otras palabras, en la consolidación de un sistema transnacional basado en la gradual interpene. tración de las sociedades nacionales. La extensión de la interdependencia alcanzada por las distintas economías nacionales puede ser apreciada con referencia al caso de los Estados Unidos. En 1960 Ia participación de las firmas estadounidenses localizadas en el extranjero en las ganancias globales de las empresas de dicho país fue solamente de $7 \%$, habiéndose elevado a alrededor de un $30 \%$ a mediados del presente decenio. Del mismo modo, Ia inversión estadounidense en el extranjero representaba el $9 \%$ de la inversión en 1957 y había llegado a representar el $28 \%$ en 1972: Las ventas al exterior 
efectuadas por la totalidad de las empresas manufactureras de los Estados Unidos representaban en 1961 el $7 \%$ del total de sus ventas, elevándose esta proporción al 13\% en 1970 (Müller, 1977-78). Esta situación es representativa de las tendencias registradas en el resto de las economías centrales. El proceso se completa debido a la aparición en el escenario internacional de un creciente número de actores -países, organizaciones internacionales y empresas o agrupaciones transnacionales- corrientes de opinión y centros de influencia, fenómeno que también ya ha sido señalado. Una manifestación obvia del proceso consiste en el hecho de que el desarrollo de cada país dependa cada vez más de los recursos, mercados, actitudes políticas, sistemas de vida y valores culturales prevalecientes en otros países, y de que sus estilos de desarrollo se encuentran cada vez más determinados por las tendencias prevalecientes en el sistema transnacional en su conjunto (Cooper, 1968; Copper, 1972; L. Brown, 1972; C. F. Bergsten, et al., 1973; S. Brown, 1974; C. F. Bergsten y L. B. Krause, 1975; Keohane iy Nye, 1977).

En un escenario internacional caracterizado por los rasgos anteriormente mencionados, los centros industriales continuan creyendo que el crecimiento económico es necesario para la solución de sus problemas y el bienestar de sus sociedades. Parecen reconocer, sin embargo, que en el pasado aquel crecimiento fue responsable de un consumo excesivo de recursos naturales, de una concentración indeseable de las actividades económicas y de un rápido deterioro del medio ambiente. La causa de estas contradicciones no es necesariamente el proceso de crecimiento en sí mismo sino su estilo, es decir, ciertas formas de vida, ciertos sectores de la actividad económica y ciertas tecnologías empleadas para la satisfacción de determinadas prioridades. De ser ello así, esos factores podrían ser corregidos no tanto a través de una detención general del crecimiento sino de un mayor énfasis en la calidad del desarrollo, perseguida a través de una intervención selectiva en el proceso. Las sociedades industriales enfrentan la alternativa de insistir en la preservación de sus formas de vida, profundizando esas contradicciones tanto a nivel interno como internacional, o de modificar su estilo de crecimiento. La percepción de que éste enfrenta ciertos límites ha generado alarmas, expectativas, presiones y medidas muy concretas encaminadas en parte a alejar esos límites y en parte a modificar aquel estilo, con el objeto de reducir las presiones que éste desencadena sobre el ecosistema. La conciencia progresiva de 
que existen límites al crecimiento económico contribuirá a hacèr factible la segunda de dichas opciones.

Al mismo tiempo, la percepción de la interdependencia, en buena medida basada en consideraciones ecológicas, está alterando los términos en que tradicionalmente se han planteado las relaciones centroperiferia, y. está imprimiendo una nueva dirección al proceso de transnacionalización que a lo largo de los últimos 15 o 20 años había promovido la integración de ambos tipos de economías en un sistema económico global.

Desde la iniciación del período de postguerra, esas relaciones se plantearon en términos de los intereses conflictivos existentes entre dos grupos de países que ocupaban una posición bien definida en la división internacional del trabajo. Dentro de aquel conflicto de intereses, los países en desarrollo luchaban por mejorar su participación en la distribución de los beneficios derivados de las relaciones económicas internacionales, a través de acciones unilaterales de carácter concesional o preferencial que debian ser adoptadas principalmente por los países desarrollados. No había una clara conciencia de que el bienestar de cada uno de esos grupos dependía, en alguna medida, del progreso de todos $-y$ del funcionamiento de la economía global en su conjunto-. Este enfoque dio por resultado la elaboración de una programa encaminado a lograr la estabilización y el mejoramiento de los precios de los productos primarios que constituían el grueso de las exportaciones de los países de la periferia a través de mecanismos de intervención en el mercado tendientes a regular su oferta; a conseguir que las manufacturas de los países en desarrollo tuvieran acceso preferencial a los mercados de los países industrializados; a incrementar e imprimir una mayor automaticidad a los flujos de financiamiento público externo otorgado en condiciones concesionales; a regular el comportamiento de las corporaciones transnacionales y el proceso de transferencia de tecnología, y en general a adoptar medidas tendientes a fortalecer la transferencia de recursos desde los países centrales hacia los países periféricos. Los modestos logros obtenidos por los países en desarrollo mediante la aplicación de ese programa durante los diez años siguientes a la primera reunión de la UNCTAD se vieron posteriormente aún más reducidos, como consecuencia de las dificultades que comenzaron a experimentar las economías centrales, de los cuales se esperaban tales transferencias.

Hoy día, sin que las medidas contempladas en dicho programa hayan pérdido su vigencia, las relaciones entre ambos grupos de 
países tienden a plantearse en términos que hagan posible complementar ese proceso de transferencia unilateral de recursos mediante la identificación de intereses mutuos que sirvan de base para la formulación de acciones recíprocamente beneficiosas (Sewel, 1978; Spero, 1977; McLaughlin, et al., 1979; Hansen, 1979, Díaz Alejandro, 1977). El reconocimiento de la existencia de una mutualidad potencial de intereses entre países desarrollados y en desarrollo ha puesto de mani: fiesto la importancia de buscar acuerdos sobre el abastecimiento y los precios de la energía y el desarrollo de los recursos naturales; la reducción del proteccionismo de los centros; la redistribución de sus actividades industriales; el acceso de los países en desarrollo a los mercados financieros internacionales y al financiamiento público de mediano y largo plazo; la búsqueda de nuevas formas de asociación con el capital extranjero y las empresas transnacionales, y sobre otras áreas de interés común. No se puede desconocer que la búsqueda que aquella reciprocidad es trabajosa, y que ella no dimanará de una suerte de "armonía natural de intereses" que no existe, sino que por el contrario supondrá negociaciones espinosas y con frecuencia conflictivas. Por encima de todo, la realización de acciones de mutuo beneficio en estas y otras áreas requerirá que los países industrializados, que no han dejado de ocupar una posición central dentro del sistema transnacional contemporáneo, acepten la introducción de reformas estructurales más o menos profundas en la economía internacional, que permitan a los países en desarrollo hacer pleno y justo uso de sus recursos naturales, acceder con sus bienes industriales a los mercados de los países desarrollados y, en general, ocupar el lugar para el cual se han estado capacitando en la nueva división internacional del trabajo que se esboza. La ausencia de estas reformas determinará que sus relaciones con los países en desarrollo se conviertan en nuevas formas de explotación y dependencia inaceptables para estos últimos, e impidirá la concertación de entendimientos de los cuales la prosperidad de las propias economías centrales depende cada vez en mayor. medida.

La conciencia de estar alcanzado ciertos límites en su proceso de crecimiento económico, que de momento ha tornado más difíciles las negociaciones económicas entre países desarrollados y en desarrollo podría favorecer en el mediano y largo plazo la aceptación de estas reformas por parte de los primeros. Los países desarrollados necesitan de los. recursos naturales de que disponen los países en desarrollo para proseguir su:proceso de industrialización; de los productos que 
estos últimos están en condiciones de exportar ventajosamente, como parte integrante de su lucha antiinflacionaria; de las condiciones que estos países poseen para desarrollar ciertas actividades productivas, por disponer de ventajas comparativas entre las cuales las consideraciones medio ambientales ocupan un lugar importante, usándolos como un elemento que los induzca a racionalizar la asignación de sus recursos; de su capacidad, en fin, para utilizar recursos financieros, importar bienes de capital y productos intermedios, y para absorber productivamente nuevas inversiones en función de su proceso de desarrollo. En otras palabras, dicha conciencia podría facilitar el reconocimiento de que una nueva estructura de ventajas comparativas y una nueva división internacional del trabajo se está abriendo paso en el mundo.

En suma, estos elementos de interdependencia están determinando que el proceso de transnacionalización esté dejando de representar un camino de una sola vía que conduce a una dependencia cada vez mayor de los países de la periferia y a su progresiva pauperización relativa, para convertirse en un factor de redistribución de capacidades y de actividades económicas -y, potencialmente, de sus correspondientes beneficios - en que los países en desarrollo podrían encontrar mayores elementos de negociación que en el pasado.

De lo que se trata, en definitiva, es que los países en desarrollo no adopten una actitud pasiva frente a este proceso, sino que lo enfrenten mediante estrategias que les permitan controlar y escoger sus formas de participación en términos de maximizar los beneficios y minimizar los costos derivados de su integración en el sistema, preservando sus estilos de desarrollo, y con ellos sus objetivos, intereses y valores. Así, por ejemplo, las presiones ejercidas sobre el ecosistema por el estilo de desarrollo prevalecientes en los países industrializados representa un riesgo para los países en desarrollo, en la medida en que en el futuro estos deban adoptar medidas encaminadas a evitar que esas presiones se repitan en su propio caso y deban absorber, por consiguiente, los mayores costos que estas medidas representen, pero los enfrentan también cón nuevas oportunidades. El desafío que encaran estos países consiste en lograr un equilibrio adecuado entre los costos de las medidas destinadas a prevenir el deterioro ecológico y los beneficios derivados de las acciones que podrían emprender con el objeto de aprovechar aquellas oportunidades. La definición del balance de beneficios y costos que cada país desee sólo podrá hacerse dentro del marco de una revisión profunda y explícita 
de sus estilos de desarrollo y, sobre todo, dependerá decisivamente de su forma de inserción en el sistema internacional.

A continuación se examinan algunas de las áreas que parecen estar llamadas a tener una influencia más determinante sobre la revisión de los estilos de desarrollo prevalecientes tanto en los centros como en la periferia $y$, muy especialmente, sobre la forma que adopten en el futuro las relaciones económicas entre ambos grupos de países.

\section{LA ACENTUACION DE LA INTERDEPENDENCIA: ALGUNAS AREAS CRITICAS}

\section{Energia}

Los estilos de desarrollo prevalecientes en los centros industriales, y las tecnologías que ellos conllevan, han tornado sus economías extremadamente dependientes de una amplia disponibilidad de recursos naturales, que tardaron millones de años en crearse y cuyas reservas son finitas $y$, por consiguiente, no renovables. Aunque más de la mitad de las reservas conocidas de dichos recursos se encuentran localizadas en los países desarrollados, éstos son responsables de cerca del $90 \%$ del consumo mundial de los mismos, por lo cual dependen estrechamente de aquellos de que disponen los países en desarrollo para el normal funcionamiento de sus economías. Esta dependencia tiende a acentuarse. Así, por ejemplo, el consumo de energía per cápita en los países industrializados es 10 veces superior al que registra en los países de ingresos medios (como Brasil o Gorea del Sur), y 100 veces superior al que pueden afrontar los países de bajos ingresos. Mientras que los países desarrollados producen 2,5 veces más minerales per cápita que los países en desarrollo, consumen 16 veces más este tipo de recursos. Consiguientemente, para asegurar su abasitecimiento, dependen de importaciones que provienen fundamentalmente de los países en desarrollo (Connelly y Perlman, 1975; Chesshire y Pavitt, 1978) .

Los grandes descubrimientos de petróleo y gas natural efectuados después de la Segunda Guerra Mundial incrementaron las reservas. mundiales, abatieron artificialmente el precio de la energía, debilitaron los esfuerzos nacionales para alcanzar la autosuficiencia energética en varios países industriales y subsidiaron, para todos los efectos prácticos, el crecimiento industrial y urbano en dichos países. En particular, ello estimuló la creación de nuevas industrias basadas en el uso intensivo del petróleo así como la expansión del automóvil y desalentó la búsqueda de nuevas fuentes de energía, induciendo o reforzando la declinación de la industria del carbón y de los sistemas de transporte públicos. Entre 1925 y 1965 el consumo de energía 
per cápita, en toneladas de carbón equivalente, aumentó de 6,2 a 9,7 en el caso de los Estados Unidos; 1,8 a 3,3 en el de Europa Occidental, y de 0,2 a 3,8 en el de la Unión Soviética.

Esta extraordinaria expansión del consumo de recursos energéticos, particularmente de petróleo, fue acompañada de precios deprimidos que implicaron un verdadero subsidio otorgado por los países productores a los países industrializados. En adición a lo anterior, el subsidio energético otorgado a estos últimos por los países exportadorè de petróleo contribuyó a 1) el desarrollo de la petroquímica y la industria de los derivados, lo que dio lugar a un proceso de sustitución de productos naturales por sintéticos, con la correspondiente réducción de la demanda y de los precios de ciertos productos básicos (minerales, maderas y fibras) que ocupaban un papel importante entre las exportaciones de los países en desarrollo; 2) la modernización y aumento de los rendimientos y la productividad de las actividades agrícolas en los países desarrollados, proceso que, unido a la protección y a los subsidios otorgados en esos países a dicho sector por el estado, impidió que los productos agrícolas de los países en desarrollo compitieran en aquellos mercados y afectó las perspectivas de desarrollo de su agricultura, y 3) la expansión de la urbanización en los países desarrollados, los cuales pueden manejar una agricultura eficiente manteniendo alrededor del $5 \%$ de su población activa empleada en ese sector, y desarrollar al mismo tiempo un tipo de urbanización altamente intensiva en el consumo de energía, cuyos patrones luego son exportados a los países en desarrollo, en donde resultan tan costosos como inapropiados.

- Esta situación cambió apreciablemente en los años 70. La demanda de energía comenzó a crecer más rápidamente que el producto en los países de la óECD y excedió los ritmos prévistos. Las importaciones estadounidenses de petróleo se elevaron en términos absolutos de 25 a 173 millones de toneladas entre 1950 y 1974 , esto es, desde el I4 hasta el $40 \%$ del consumo total de petróleo de ese país, constituyéndose en una de las principales causas cle la crisis. La industria del. carbón entró en dificultades cada vez más serias y el desarrollo de la energía nuclear no avanzó al ritmo esperado. A principios del decenio se consideraba inevitable una tendencia al alza de los precios y la emergencia de un mercado de vendedores, lo que en efecto ocurrió a partir de 1973 .

Hasta ahora esta tendencia ha sido objeto de interpretaciones bastante contrapuestas (Tomassini, 1978), Para algunos el petróleo 
sería "la excepción", para usar el título de uno de los trabajos aparecidos inmediatamente después de la crisis energética (Krasner, 1974), y su comportamiento no sería relevador de una tendencia ni se reproduciría fácilmente en el caso de los demás recursos no renovables. Para otros observadores la crisis del petróleo sería solamente la cabeza del iceberg de un problema que tiende a generalizarse para. el conjunto de las materias primas.

Aunque es frecuente que en los países industrializados surjan voces desde diversos ángulos que abogan por el retorno a los buenos tiempos de la energía barata, sea con base en razonamientos económicos neoclásicos (los monopolios son malos y el costo de producción del petróleo en el Medio Oriente es bajo), o simplemente en términos de consideraciones de poder, es prácticamente imposible que estas condiciones se repitan. En efecto, desde la perspectiva que da el tiempo transcurrido después del alza de los precios del petróleo, se ha ido poniendo de manifiesto que este fenómeno con la anuencia - e incluso el estímulo- de las empresas petroleras y de algunos países industrializados, principalmente de los Estados Unidos. Así, por ejemplo, un año antes de las primeras alzas violentas en los precios del combustible, se celebró una conferencia en Algeria, a la que concurrió úno de los expertos más influyentes en el Departamento de Estado en el campo petrolero, James Akins, quien en aquella oportunidad anticipó lo que sería el análisis oficial de Ios Estados Unidos, según el cual era inevitable un alza de los precios del petróleo frente a la falta de fuentes alternativas inmediatas para. el suministro de ènergía; y como una manera de estimular el desarrollo de esas fuentes. (Oppenheim, 1977). Esta actitud se basaba en la percepción de un inminente amenaza de escasez generalizada de energía ry recursos naturales a escala mundial.

Diversos sintomas y voces de alarma han contribuido a difundir esta percepción. El primer informe al Club de Roma previó que la totalidad de las reservas de combustibles fósiles (que incluyen carbón, petróleo y gas natural) se agotarán dentro de los próximos 150 a 200 años y que el petróleo, en particular, lo hará dentro de los próximos 20 ó 30 años (Meadows, 1972). Este tipo de estimaciones incluso condujeron a prescripciones de politica encaminadas a detener y aun a reducir el desarrollo. Contrastan estas proyecciones con apreciaciones más optimistas, sea de tono moderado (Dumont, 1974; Mesarovic y Pestel, 1974), o abiertamente optimistas, como las del Hudson Institute (Kahn, 1976) y los escritores soviéticos. Sin embargo, en el 
balance, pocas dudás caben de que éste constituye el principal desafío que actualmente enfrenta la comunidad internacional, un desafío que deberá ser respondido mediante una combinación de acciones que incluyan, tanto programas encaminados a la búsqueda de fuentes alternativas de energía como a promover la conservación o ahorro del recurso.

No sería prudente que la comunidad internacional se limitara a promover esfuerzos para el desarrollo de los recursos energéticos y la búsqueda de fuentes alternativas de energía, por grandes que ellos fueren, si no estuvieran acompañados de políticas conservacionistas. No existen razones para pensar en forma rígida que en el futuro el crecimiento económico, particularmente en los países industrializados, registrará la misma relación entre crecimiento y consumo de energía que en el pasado. Entre 1925 y 1965 hubo considerables variaciones entre los países. Los requerimientos energéticos del crecimiento fueron más bajos durante ese período para países industrialmente maduros, como Bélgica, Alemania, el Reino Unido y los Estados Unidos, que para países más recientemente industrializados, tales como Canadá, Italia, Japón, Holanda, Suiza, Suecia, la Unión Soviética y Yugoeslavia. En 1975 se registraban considerables diferencias entre los distintos países en cuanto a la cantidad de energía requerida para genexar cada unidad de producto, variando entre 2,7 y 13 kilos de carbón equivalente en los casos de Canadá, el Reino Unido, Estados Unidos y la Unión Soviética, y entre 1,2 y 2 kilos en los casos de Francia; Italia, Japón, Holanda, Suecia, Suiza y Yugoeslavia (Darmastadter, citado en Freeman y Jahoda, 1978): Estas diferencias tienen que ver fundarentalmente cori el grado de desarrollo o la madurez de las distintas economías. En todo caso, estas observaciones sugieren la existencia de una estrecha correlación entre el grado de madurez industrial de los países y los requerimientos energéticos de su ulterior proceso de crecimiento económico. Lo que nos interesa destacar es que, naturalmente, esta correlación es más rígida en el caso de los países en desarrollo.

En efecto, un aspecto fundamental para el fluido funcionamiento de la economía internacional e incluso para la paz mundial se refiere a las diferencias interregionales en materia de perspectivas de abastecimiento energético, y a las tensiones a que esas diferencias pueden dar lugar, debido a la posición dominante de los Estados Unidos y la Unión Soviética en la oferta de combustibles fósiles, a la vulnerabilidad de Africa y América Latina, y al alto grado de dependencia 
del Sudeste Asiático. A esta conclusión lleva un cálculo consistente en dividir el tamaño de las reservas últimamente recuperables de petróleo y gas natural de cada una de esas regiones por sus necesidades energéticas acumuladas hasta el año 2000, estimadas sobre la base de la presunción de que hasta esa época el consumo se elevará gradualmente hasta alcanzar un volumen de 6 tce* per cápita (Chesshire y Pavitt). Según ese cálculo, la Unión Soviética y Europa Oriental podrán cubrir sus propias necesidades por un factor de entre 30 y 50 . Los Estados Uniclos podrán hacerlo por un factor de entre 15 y 26. Las necesidades de China están cubiertas solamente por una factor entre 1,4 y 3,6. Europa Occidental, por un factor de entre 2 y 5 . La posición de Africa y América Latina es más incierta, y la región más dependiente es el Asia Septentrional.

De estos hechos es posible inferir algunas de las presiones a que se verán sujetas las relaciones internacionales durante los próximos decenios, particularmente las relaciones entre los pafses desarrollados y los países en desarrollo, como consecuencia de los problemas energéticos. Entre estos problemas se cuentan la evolución de la demanda global y de los precios de los recursos energéticos, de los cuales dependen vitalmente las perspectivas del desarrollo económico y las necesidades de financiamiento de los países de la periferia; las perspectivas de adoptar políticas conservacionistas y estilos de desarrollo consis. tentes con ellas en los grandes centros industriales, lo que a través de los patrones de producción y de consumo y de la tecnología proveniente de estos centros influirá a su vez en los estilos de desarrollo que adopten los países de la periferia, y por consiguiente en su posibilidad de mantener un ritmo de crecimiento adecuado y de lograr una distribución más igualitaria del ingreso; la combinación de fuentes de energía que en el mediano y largo plazo desarrollen los países centrales, y el grado de concentración del poder y de los recursos financieros y tecnológicos requerida para desarrollar cada una de esas fuentes, lo que determinará un margen de decisión de que dispongan a este respecto los países periféricos; las consecuencias medio ambientales del desarrollo de cada una de las fuentes alternativas señaladas más arriba, y otros.

Recursos naturales.

Conviene detenerse también en los problemas de otros recursos no

*Toneladas de carbón equivalentes. 
renovables, particularmente los de origen mineral. La gama de factores de los cuales depende la evolución de estos problemas es muy amplia y no puede ser planteada aquí: la disponibilidad de estos recursos; los costos, la tecnología y la concentración geográfica de las actividades de exploración $y$ extracción; los requerimientos de las actividades mineras en términos de inversión, transporte y comercialización; la organización de las actividades de procesamiento de los minerales; el uso final de los productos; las posibilidades de conservación, sustitución y reciclaje, y los márgenes dentro de los cuales podrían modificarse los estilos de desarrollo prevalecientes a fin de adoptarse a la disponibilidad de materiales, son algunos de ellos.

La demanda mundial de minerales ha crecido muy rápidamente a partir de $1900 \mathrm{y}$, muy en especial, de 1950. Así por ejemplo (y en mi les de toneladas), la de acero creció de 28.000 a 169.000 y a 590.000 , respectivamente; la del aluminio, de prácticamente 0 a 1.510 y a 10.000; la de cobre de 500 a 2.520 y 6.310 , y así sucesivamente. El ritmo de crecimiento de la demanda de esos 3 productos durante el periodo de 1950 a 1970 , por ejemplo, fue de $6,5 \%, 10,1 \%$ y $4,7 \%$, en comparación con un ritmo de crecimiento de $3,0 \%, 8,9 \%$ y $2,4 \%$ correspondiente al período de 1925-1950 (Page, 1978).

Contrariamente a lo que se supone, las actividades mineras están concentradas en los países industrializados. Sin embargo, dado que los países industrializados consumen considerablemente más materiales que los que producen, particularmente en el caso de los Estados Unidos y la Unión Soviética, los países en desarrollo desempeñan un papel importante en el comercio internacional de minerales. Lo que es más, su papel como productores se ha fortalecido considerablemente de principios de siglo, en que era muy limitado, debido a la gran reorientación que han experimentado las inversiones hacia minas localizadas en estos países. Así, por ejemplo, entre 1899 y 1974 la participación de los países industriales en la producción de hierro, cobre y plomo disminuyó del $99 \%$ al $63 \%$, del $90 \%$ al $56 \%$ y del $90 \%$ al $71 \%$, respectivamente, en tanto que la participación de los países en desarrollo aumentó de $1 \%$ a $37 \%, 10 \%$ a $44 \%$ y $10 \%$ a $29 \%$ en esos mismos rubros. Esta tendencia se ha acelerado en forma perceptible en el decenio de los años 70, colocando en el primer plano de las preocupaciones los problemas relacionados con la nacionalización de las actividades productivas, los regímenes adoptados por los países productores en materia de impuestos y regalías, los arreglos para la fijación de precios y la comercialización de los productos y, en gene- 
ral, las modalidades adoptadas por los contratos entre los países productores y los inversionistas extranjeros.

La exigencia de mejorar la distribución de los beneficios derivados de las actividades de extracción y procesamiento de minerales entre países productores y consumidores continuará presionando hacia la búsqueda de nuevas formas de contratación entre ambos grupos de países o entre las empresas transnacionales y los países productores. Ciertamente, la magnitud y orientación de esas presiones dependerá del balance a que se llegue entre incrementar la extracción de minerales y consumir menos recursos, particularmente en los países industriales que son los principales consumidores. Ello, a su vez, dependerá de la evolución que experimenten sus estilos de desarrollo. La cantidad de materiales requerida para producir determinados bienes ha declinado en muchos casos con el tiempo. La posibilidad de reducir el consumo de materiales introduciendo economías en su uso parece mayor que las que podrían abrir el reciclaje de materiales ya utilizados. En todo caso, las posibilidades de implementar con éxito políticas conservacionistas parecen más inciertas que la de que el desarrollo de los centros industriales continúe presionando sobre el uso de recursos minerales, aun cuando sea previsible que el ritmo de crecimiento de esas economías disminuya por un período bastante prolongado e inciuso sean imaginables cambios de ciertas significación en sus estilos de desarrollo.

En suma, pues, existe una percepción cada vez más acentuada de que la oferta de recursos no renovables a bajos costos no será suficiente para mantener y aún acentuar en forma indefinida los estilos de vida que hoy prevalecen en las sociedades industrializadas ni para elevar los niveles de vida en los países en desarrollo, cuyos requerimientos en este campo son crecientes, debido a que su principal im. perativo consiste precisamente en acelerar su desarrollo, y al incremento de su población. Sin embargo, las pautas imperantes en materia de exploración y explotación de recursos naturales han sido hasta ahora inadecuadas.

Las inversiones efectuadas en exploración han sido inadecuadas. Se han concentrado en unos pocos países, que ya han sido objeto de un reconocimiento bastante exhaustivo y en donde las posibilidades de encontrar nuevas fuentes de recursos son pequeñas, mientras el resto del mundo permanece prácticamente inexplorado. Cerca del $90 \%$ de los gastos en exploración, durante los últimos años, se han realizado en los países desarrollados. Esa distribución es ineficiente. Los países 
desarrollados se esfuerzan por mantener esa pauta, ya que desean preservar su independencia en materia de recursos, y temen perder su control sobre esas fuentes, dando la espalda al hecho de que viven en un mundo cada vez más interdependiente.

La explotación de esas fuentes adicionales de recursos, localizadas en los países en desarrollo, ha dependido fundamentalmente del capital extranjero y de las empresas transnacionales, las cuales han conducido sus actividades de tal manera que han creado "enclaves" aislados del resto de la economía y en poco o nada han contribuido al desarrollo de los países anfitriones, que son precisamente los propietarios del recurso. Ello ha dado origen a una secuela de conflictos y tensiones. El reconocimiento gradual de que los países en desarrollo deben disponer soberanamente de sus recursos naturales ha tendido a disipar esas tensiones. Pero el desarrollo de los recursos naturales de que dispone el tercer mundo requiere que la comunidad internacional no solamente acepte la soberanía de esos países sobre sus propios recursos sino también que presten más atención a la forma que adopta el financiamiento de esas inversiones, a la estabilidad de los mercados de productos básicos, al desarrollo de actividades encaminadas al procesamiento de dichos recursos en los propios países productores y al comportamiento de las corporaciones transnacionales que operan en ese campo. Ello supone, sobre todo, el fortalecimiento de la capacidad negociadora de los países en desarrollo, la cual debe basarse en la diversificación de sus fuentes de financiamiento, en la búsqueda de nuevas formas de asociación con el capital extranjero, de su progresivo control sobre los canales de comercialización de sus productos y de un creciente conocimiento técnico y geológico. Por lo demás, sólo aquel incremento de su capacidad negociadora les permitirá obtener un balance adecuado entre su interés en desarrollar los recursos naturales de que disponen y la necesidad de proseguix una política de conservación que atienda a las necesidades del desarrollo del país a largo plazo, prestando debida consideración a los requerimientos ecológicos.

El establecimiento de una nueva relación entre consumidores $y$ productores, en el campo de los recursos naturales, permitirá también revisar los criterios en que durante largo tiempo se ha asentado aquí la política de precios. A fin de paliar los efectos del gradual agotamiento de sus propios recursos y su creciente dependencia con respecto a productos importados, los países industrializados han desarrollado una política que les ha permitido obtener materias primas subsidia- 
das, basada en una concepción del crecimiento económico y en un sistema de precios que identifica la riqueza con los "flujos" de bienes y servicios que normalmente se contabiliza en el cómputo del producto nacional y excluye los "inventarios" representados por la dotación de recursos naturales y de bienes culturales que constituyen el patrimonio hereditario de una sociedad. Es más, esos países han logrado hacer que este último acervo forme parte de su propio "inventario", mediante diversos arreglos encaminados a asegurar su control sobre los recursos naturales de que dispone el resto de la comunidad internacional. Mientras estos conceptos económicos y estas realidades politicas prevalezcan será difícil pensar en precios justos, estables y remunerativos para la producción basada en los recursos naturales de que disponen los países en desarrollo. Para contrarrestar estas tendencias se requiere una estrategia encaminada a acentuar la autonomfa del clesarrollo de los países periféricos y a lograr el reconocimiento de que, dentro del sistema de precios, es necesario considerar la amortización de los recursos utilizados para la producción de esos bienes, tomando como base su valor de reposición, ya sea por la vía de la fijación de sus precios, del establecimiento de impuestos o de una combinación entre éstas y otras medidas. La inclusión del costo de amortización en la fijación de los precios de los recursos naturales debería efectuarse de una manera no muy diferente a la que se aplica tratándose de equipos o bienes de capital. Keynes reconocía que el "costo de uso" debía aplicarse no sólo a estos últimos sino también a las materias primas, ya que con ellas ocurre lo mismo que con los primeros, en donde "para decidir su escala de producción el empresario tiene que hacer una opción entre usar su equipo ahora o preservarlo para ser usado después". De este modo, "la decisión de utilizar los recursos naturales es considerada, por lo tanto, como similar a la de desinvertir en el rubro de bienes de capital, mientras que la búsqueda de nuevas fuentes de recursos naturales es simplemente una forma de inversión" (Davidson, 1979; Mishan, 1971).

En todo caso, tal vez la lección más importante que se deriva de las tendencias anotadas en materia de recursos no renovables consista en la inconveniencia de que los países en desarrollo continúen centrando su estrategia exclusiva o principalmente en la búsqueda de mecanismos para lograr la estabilización y el mejoramiento de los precios de sus productos básicos de exportación, la cual debe ir acompañada de estrategias orientadas a promover el desarrollo de sus recursos naturales, que presten atención a las oportunidades que 
se abren para hacerlo bajo modalidades más favorables que en el pasado, en un previsible contexto de escasez.

\section{Industrialización y división internacional del trabajo.}

La industrialización ha sido el principal motor del extraordinario ritmo de expansión económica que ha vivido el mundo desde el siglo pasaclo pero, muy particularmente, a partir de la segunda postguerra. Como resultado de la división del mundo entre unos pocos centros industriales y un gran número de países periféricos a los cuales se reservó el papel de suministrar las materias primas que necesitaban los primeros para proseguir su proceso de crecimiento e industrialización, división cuyo establecimiento se aseguró mediante amplias operaciones coloniales, la capacidad industrial del mundo se encuentra muy desigualmente distribuida, concentrándose en más de un $90 \%$ en los países centrales. Contra ese telón de fondo debe apreciarse la magnitud del desafío que implica la meta establecida en la conferencia de la oNuDi en Lima, en 1975, en el sentido de que a fines del presente siglo la participación de los países en desarrollo en la producción industrial mundial debería aumentar al 25\%. EI cumplimiento de esta meta requeriría un proceso de redistribución industrial de grandes proporciones.

Se entiende por redistribución industrial el traslado de una industria existente desde una localización a otra en respuesta a factores de mercado o a una intervención gubernamental. No hay duda de que se trata de un proceso que se ha iniciado y que incluso se está desarrollando en forma cada vez más acelerada, como reacción a ciertos factores que predominan en los centros, entre los cuales se cuentan la existencia de costos de producción en aumento como consecuencia de los niveles salariales que predominan en esas sociedades y de la magnitud del gasto público, tasas de rentabilidad declinantes, menor inversión en esos países y. reorientación de la misma hacia otras áreas y limitaciones derivadas de la necesidad de preservar o remediar el deterioro causado al medio ambiente con las actividades económicas, lo que conlleva la adopción obligatoria de medidas para el control de la contaminación, que encaracen las inversiones respectivas.

Como consecuencia de estos y otros factores, ha ido tomando cuerpo en muchos círculos la convicción de que la distribución de actividades económicas entre los distintos países y, muy particularmente entre países desarrollados y países en desarrollo, habrá de 
enfrentàr una mutación profunda. Las raíces estructurales que parece tener el cuadro recesivo e inflacionario que presentan las economías centrales, en un escenario de inestabilidad crónica, estaría estimulando ese proceso. Por ello desde muchos ángulos se señala que la aceptación de políticas de ajuste, y de sus costos, constituye el principal desafío que hoy enfrentan Ios países industrializados (Institute of Social Sciences, 1977; Evers, et al., 1977; Malmgrem, 1977; Katzenstein, 1977; Helleiner, 1977; Grunwald, 1978, y entre la literatura latinoamericana, Villanueva, 1978; González, 1979; Donger, et al., 1979; Hill y Tomassini, 1979). De hecho, este proceso yya se ha iniciado en forma acelerada.

Cabe añadir a estos factores la existencia de una situación recesiva cuyas perspectivas de recuperación parecen lentas, con un nivel de desempleo que dificulta los cambios que habría que introducir en esas economías, incluyendo la automatización de un número creciente de procesos industriales. La misma situación, al incidir en la rentabilidad del capital, inhíbe la inversion y promueve la salida de capitales en busca de otras localizaciones más rentables. De ella se deriva también la existencia de ramas industriales relativamente retrasadas y sometidas a la creciente competencia internacional de un número cada vez mayor de países en desarrollo. Los problemas vinculados a la disponibilidad y la seguridad en el abastecimiento de recursos. naturales, particularmente de origen energético, deben incluirse en este escenario. $\mathrm{El}$ hecho de que un elevado nivel de desempleo forme parte del síndrome anotado no excluye el surgimiento de dudas acerca de la disponibilidad a largo plazo de mano de obra abundante $y$, sobre todo, barata, la que hasta ahora fue suministrada por las migraciones. Los costos de preservación del medio ambiente, a que se refiere más adelante este documento, es otro elemento central de este escenario. Todos estos elementos deben ser apreciados a la luz de la lentitud con que históricamente ha tenido lugar la incorporación de nuevas tecnologías.

Estas tendencias encontraron su contrapartida en la creciente diferénciación observable entre los países en desarrollo, y en la emergencia entre esos de un número cada vez mayor de países en rápido proceso de industrialización o de "desarrollo intermedio". Durante los últimos años algunos países de Europa Meridional y Oriental, del Oriente Asiático y América Latina han desarrollado rápidamente su capacidad pàra producir manufacturas altamente competitivas en Ios mercados mundiales. Este fenómeno, que alguna vez fue descrito como: "la emergencia de dos o tres Japones" en el campo comercial; 
está adquiriendo cada vez mayor impörtancia (Banco Mundial, 1979; Tomassini, 1979). En general, estos países pueden definirse como aquellos en que la producción industrial, considerada como aquella que supera las primeras etapas del procesamiento local de los recursos naturales, excede cierta proporción del producto interno bruto $\mathrm{y}$ crece más xápidamente que en los países ya industrializados, sea que esta producción se destine a la exportación o a sustituir importaciones. La creciente importancia de las manufacturas como porcentaje de sus exportaciones totales, el valor per cápita de sus exportaciones de bienes industriales y la participación de "productos complejos" en este tipo de exportaciones, constituyen otros tantos indicadores que contribuyen a la definición de estos países, los que son vistos por los países industrializados como competidores cada vez más serios en los mercados internacionales (Balassa, 1977, IBRD, 1979; Kahn, 1979; CEPAI, 1979).

Como consecuencia de las tendencias anteriormente señaladas, el esquema internacional de ventajas comparativas entre países desarrollados y países en desarrollo se encuentra sujeto a cambios profundos.

Estos cambios se manifiestan primeramente en la estructura del comercio internacional. Las exportaciones de productos manufacturados efectuadas por los países en desarrollo han estado creciendo mucho más rápidamente de lo que se había previsto: la tasa promedio de crecimiento anual subió de un $12 \%$ en el período 1960-1966 a un $25 \%$ en el correspondiente a $1967-1973$, lo cual se compara con un $17 \%$ para el caso de las naciones desarrolladas durante el último período (Balassa, 1977). En el de América Latina, las exportaciones de manufacturas aumentaron 23 veces durante los dos decenios comprendidos entre 1955 y 1974 , en contraste con un aumento de 11 veces para el mundo considerado en su conjunto. Por lo demás, la competitividad de las manufacturas producidas por los países en desarrollo no sólo se manifiesta en los mercados internacionales, sino que está dando lugar a nuevas formas de sustitución de importaciones en sus propios mercados, sustituciones que están comprendiendo un número creciente de bienes de capital y materiales industriales básicos, de los cuales los países industrializados habían sido los principales proveedores. El recrudecimiento del proteccionismo en estos últimos países, otro tema que escapa a los alcances de este documento, ha sido su respuesta frente a este fenómeno.

Al mismo tiempo, desde fines del decenio pasado la participación de los países en desarrollo en la industrialización mundial comenzó a incrementarse y a adoptar modalidades nuevas consistente en la 
absorción de un número creciente de actividades industriales anteriormente localizadas en los países desarrollados, como las que se señalaba más arriba. En efecto, a partir de esa época las firmas industriales de estos últimos países comenzaron a compartir su producción con subsidiarias o empresas independientes localizadas en los países en desarrollo, aprovechando las ventajas de que estos disponian en cuanto a niveles salariales, impositivos, disponibilidad de recursos naturales, regulaciones ambientales menos estrictas o el otorgamiento directo de subsidios, con lo cual al mismo tiempo disminuían sus riesgos como consecuencia de una mejor distribución internacional de sus actividades. Debido a esto comenzó a desarrollarse un activo intercambio de los componentes y procesos requeridos para llegar al producto final en adición al comercio internacional de los mismos. Esta nueva división del trabajo permite racionalizar ciertas industrias. ineficientes en los centros y hace posible promover la industrialización en la periferia, dando lugar al logro de mutuos beneficios, en concordancia con las tendencias que se señalaban en la primera parte de este documento. Por otra parte, la redistribución internacional de actividades industriales contribuye a dar respuesta a la tendencia proteccionista en los centros, en la medida en que las importaciones de productos industriales complementarios encuentren menos resistencia que la importación de bienes finales producidos en el extranjero. Un ejemplo de este fenómeno se encuentra en la subcontratación de firmas estadounidenses con subsidiarias mexicanas: en 1975 estos arreglos contribuian con más de 1.000 millones de dólares a las exportaciones industriales mexicanas, es decir, con casi la mitad del valor de sus exportaciones totales de manufacturas.

Una de las consideraciones que está detrás de este proceso consiste en la conveniencia de hacer un uso más racional de la capacidad absortiva del ecosistema a nivel mundial. Para que esta capacidad sea utilizada en forma eficiente, debe ser concebida de una manera similar a las ventajas comparativas que tradicionalmente han determinado la división internacional del trabajo, como por ejemplo el capital y la mano de obra. En otras palabras, siendo la capacidad de absorción del medio ambiente una condición necesaria para el desarrollo de ciertas actividades industriales, estas últimas deben ser distribuidas tomando en cuenta no solamente las diferencias referentes a la dotación de capital y de trabajo entre los distintos países sino también su dotación natural de capacidad de asimilación medio am: bientaI, definida como la capacidad del medio ambiente natural para absorber y neutralizar desechos industriales. Las disposiciones 
deI Glean Air Ammendments Act aprobada por el congreso de los Estados Unidos en 1970 constituye un buen ejemplo de regulaciones ambientales susceptibles de influir en la localización de nuevas industrias.

De hecho, un proceso cada vez más importante de redistribución industrial está teniendo lugar en los Estados Unidos y, en forma más acelerada, en Europa (particularmente en Alemania Occidental) y el Japón. Las ramas en que esta tendencia es más notoria -en la mayor parte de las cuales tiene especial gravitación la naturaleza contaminante de las actividades respectivas- incluyen las industrias pesadas (siderurgia, refinación, petroquímica y fertilizantes) y las industrias contaminantes propiamente dichas, a saber, la industria química y la de la pulpa y el papel. La producción naval, metal mecánica y textil están siendo igualmente desplazadas. Toda la industria de transformación de materias primas, en general, está siendo transferida fuera de páses como Japón y Alemania Occidental. Ya sea como consecuencia de las fuerzas del mercado o de decisiones gubernamentales, en donde las consideraciones medio ambientales tienen un gran peso, no menos del $30 \%$ de las nuevas inversiones desde ahora hasta el año 2000 se radicarán en países en desarrollo, lo que representa un volumen de alrededor de 75.000 millones de dólares por año.

Finänciamiento externo.

Otra de las áreas en que la creciente interdependencia entre Ios países en desarrollo y los desarrollados se aprecia más claramente es la que se refiere al financiamiento externo. En la actualidad los países del Tercer Mundo han acumulado una deuda externa cercana a los 200 mil millones de dólares. Cerca de la mitad de esa cifra corresponde a América Latina. Brasil y México, por su parte, son responsables de aproximadamente la mitad de las obligaciones que pesan sobre la región.

El hecho de que el aumento de la deuda externa de los países en desarrollo ( $o$, al menos, de aquellos relativamente más avanzados) constituya un claro indicador de su creciente relación de interdependencia con los países desarrollados se ve reforzado por la apreciación de que su rápido crecimiento durante los últimos años no se debió tanto a las necesidades prevalecientes en la periferia como a las tendencias observables en los propios centros industriales.

EI decenio de 1960 presenció la emergencia de un pujante mercado de euiomonedas caracterizado, entre otras, cosas, por el creciente 
interés por operar con los países en desarrollo. El rápido incremento de los depósitos en euromonedas, el aumento del número de bancos que operaban en esos mexcados y la consiguiente intensificación de su competencia, y su deseo de diversificar sectorial y geográficamente sus colocaciones y de distribuir mejor sus riesgos, estimuló la búsqueda de nuevos clientes y tornó elegibles a acreedores que antes no lo hubieran sido. Por otra parte, el lento crecimiento de la demanda crediticia por parte de las empresas de los países industrializados fue acompañada por un apreciable aumento en los precios de los productos básicos de exportación de los países en desarrollo y por un consiguiente mejoramiento de sus balanzas de pago, todo lo cual convirtió a esos países en clientes potencialmente atractivos a los ojos de los banqueros internacionales (Griffith Jones).

Al mismo tiempo, se acentuó en los países en desarrollo (particularmente en los países intermedios) la tendencia a recurrir al financiamiento externo, a fin de hacer posible la ejecución de grandes programas de inversión que formaban parte esencial de sus planes nacionales de desarrollo y que incluían un alto componente importado. Paralelamente, los gobiernos de esos países comenzaron a preferir los préstamos privados a la ayuda externa de origen público, por considerar que los primeros eran otorgados en condiciones más liberales, tanto en lo que respecta al uso de Ios fondos como en el grado de intervención de los acreedores en cuanto a la forma en que debía ser manejada la economía de los países prestatarios. Esta opción se vio reforzada por la erosión que experimentó la confianza de los países en desarrollo frente a la inversión extranjera directa, crecientemente reputada como fuente de rentas monopólicas y un importante factor de dependencia externa.

El hecho de que el endeudamiento externo de los países rel Tercer Mundo haya continuado aumentando a lo largo de todo el decenso de 1970 - durante el cual los flujos de financiamiento externo hacia América Latina duplicaron sus niveles anteriores alcanzando unos 15 mil millones de dólares por año- sólo significa que esos países, particularmente aquellos que ya habían alcanzado etapas de "desarrollo intermedio" optaron por postergar los efectos depresivos derivados del incremento de los precios del petróleo, endeudándose para financiar sus importaciones y para asegurar de esta manera, la continuidad de su expansión económica. Pero no debe olvidarse que esa expansión les permitió desempeñar un insospechado papel como un factor adicional de reactivación de la economía mundial, precisamente en un período en que esta atravesaba por una coyuntura 
muy difícil, y de atenuación del ciclo recesivo de los centros (Sewell, 1978).

\section{PRINGIPAIES ALTERNATIVAS DE LOS PAISES EN DESARROLLO ${ }^{1}$.}

En este trabajo se sustenta que los términos en que tradicionalmente se plantearon las relaciones centro-periferia se han modificado significativamente a lo largo de los dos últimos decenios, como resultado del avance del proceso de transnacionalización que ha tenido lugar a escala global, dando Iugar a una relación de interdependencia entre todos los países del mundo. Se sostiene también que la crisis del sistema transnacional contemporáneo, determinada por factores que ya han sido analizados, ha acentuado esa relación de interdependencia. Se sostiene, por último, que hasta cierto punto la interdependencia no solamente es una realidad entre los países industrializados sino también entre éstos y los países en desarrollo, aunque se trate de una "interdependencia entre desiguales".

Como consecuencia de lo anterior, el mejoramiento de las relaciones entre ambos grupos de paises se concibe cada vez más dentro del marco de la evolución de la economía internacional en su conjunto. No depende, por lo tanto, solamente de los programas de cooperación internacional puestos en juego por los países industrializados. Depende también, y cada vez en mayor medida, de las reformas estructurales que éstos acepten introducir en el sistema, con el objeto de abrir paso a una división internacional del trabajo más acorde con la nueva estructura de ventajas comparativas que está esbozándose en el mundo, como consecuencia de la crisis señalada, y en la cual los países en desarrollo ocupen el lugar para el cual se han estado capacitando durante los últimos decenios.

De esta conclusión se deriva, entre otros corolarios, la noción de que el ritmo y estilo del desarrollo de los países de la periferia estará cada vez más estrechamente asociado al grado y la forma que adopte su integración al sistema transnacional. Dicha integración entraña al mismo tiempo riesgos y beneficios para ellos. Estos países enfrentan el desafío de encontrar un equilibrio adecuado entre los costos que podría infligirles ese proceso y los beneficios que podrían obtener de una participación más amplia, agresiva y diversificada en el sistema. Estos costos y beneficios desbordan, ciertamente, la esfera económica.

${ }^{1}$ Las consideraciones que siguen se basan en un documento inédito de Osvaldo Sunkel, titulado: "Opciones de inserción de Ios paises subdesarrollados en el sistema internacional". Santiago, 1978. 
La sugerencia que se quiere dejar planteada al término de este documento consiste en que el proceso de integración de los países periféricos en el sistema económico transnacional no acarrea necesariamente consecuencias puramente negativas o positivas ni responde exclusivamente a los intereses o designios de aquellos países que ocupan una posición central en el sistema. Se trata, por el contrario, de un proceso que posee un margen de ambigüedad considerable, desde el punto de vista de sus consecuencias para los países de la periferia, y frente al cual éstos pueden asumir un papel pasivo o activo (IgIesias, 1979). Lo anterior debería inducir a esos países a rechazar tanto una estrategia de integración indiscriminada en la economía transnacional en formación, como una de aislamiento internacional o "desarrollo separado", explorando la perspectiva de articular estrategias de "participación selectiva" en el sistema. Ello supone la posibilidad de combinar diversos grados de apertura $y$ de interrención dentro de una gama de alternativas como la que se sugiere a morlo general en el siguiente diagrama:

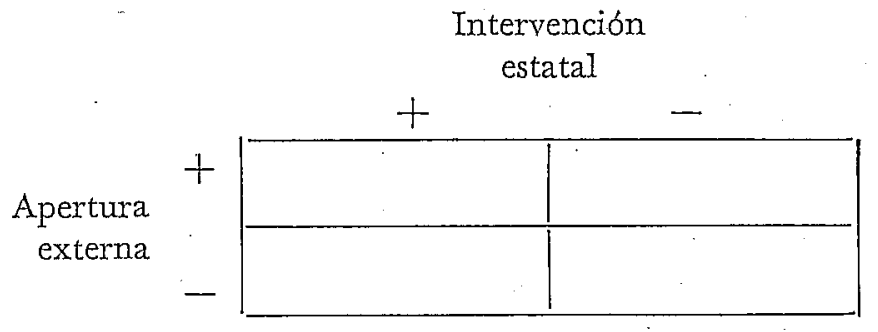

En forma simplificada, ello permitiría distinguir 4 tipos de estrategia externa: 1) apertura con intervención; 2) apertura sin intervención; 3) aislamiento (o protección) con intervención, y 4) aislamiento sin intervención. El concepto de intervención es utilizado como el ejercicio de la capacidad nacional -o del estado- para regular la aplicación de la estrategia.

El margen de maniobra para la aplicación de uno u otro tipo de estrategia dependerá, obviamente, de las características de cada país, incluyendo el tamaño y grado de desarrollo de su economía, la forma que tradicionalmente han adoptado sus relaciones económicas externas, su localización geográfica y su desarrollo social e institucional, entre otras. Es evidente que un país en desarrollo cuya economf́a 
haya adquirido ciertas dimensiones, cuente con un mayor apoyo relativo en el marco interno, posea cierto grado de conglomeración industrial, esté haciendo uso de economías de escala, cuente con un desarrollo científico y tecnológico - aunque incipiente- propio, posea cierto grado de desarrollo social, se apoye en un sistema institucional y financiero bien establecido, y haya desarrollado durante un período prolongado relaciones económicas externas con mercados estables y disponga de cierto poder de negociación frente a terceros, contará con un margen de maniobra muy superior a un país pequeño, que no reuna estas condiciones y que tenga mayor necesidad de especializar su economía en función de su localización geográfica, de sus recursos naturales o de su abundancia de mano de obra no calificada, y cuyas relaciones económicas externas sean altamente concentradas $y$, por lo tanto, vulnerables.

Estas características, y los márgenes de maniobra consiguientes, no sólo dependen de la dimensión y el grado de desarrollo de cada economía sino también de su estructura. Las diferencias observables en cuanto a la estructura productiva y la composición de las exportaciones de un país en desarrollo pueden ser explicados, en buena medida, por referencia al tamaño de su población y a su ingreso per cápita. Otra variable que influye en este plano radica en su dotación de recursoș naturales. "Si uno conoce el ingreso per cápita, la población y la dotación de factores (cuantificándola de alguna manera) para un país en desarrollo determinado, uno debería estar en condiciones de anticipar en forma valedera las características de la estructura productiva y del comercio exterior de ese país, lo cual a su vez juega un papel central, si bien no necesariamente determinante, en la formulación de su políticá económica intẹnnacional". (Diaz: Alejandró, 1977) .

La forma de insersión internacional de cada país $-\mathrm{y}$, por consiguiente, el grado de autonomía relativa de su respectivo proceso de desarrollo- está estrictamente conectada con las opciones que dicha sociedad adopte respecto a las restantes dimensiones en función de las cuales es posible caracterizar su estilo de desarrollo.

En otro lugar se ha señalado que el estilo de desarrollo predominante en una sociedad determinada se puede caracterizar en función de las opciones que ésta adopte en relación con diversas dimensiones, entre las cuales se cuentan a) el crecimiento económico, b) el desarrollo social, c) la participación poltica, d) la identidad cul- 
tural, e) la sustentabilidad ecológica y f) la autonomía nacional². En ese lugar se postulaba la existencia de una necesaria correlación entre las posiciones adoptadas por un país determinado frente a las diversas dimensiones anteriormente mencionadas.

Así por ejemplo, una sociedad que procure lograr una integración irrestricta en la economía mundial contemporánea probablemente privilegiará el crecimiento económico a corto plazo y tendrá un grado relativamente elevado de concentración del ingreso, un bajo nivel de participación política, una débil conciencia de identidad cultural y una forma deficiente de sustentación ecológica, todo ello acompañado, como es obvio, de un escaso margen de autonomía nacional. En otras palabras, esa sociedad vivirá un proceso de acelerado crecimiento económico basado en una gran apertura externa, con un alto grado de concentración del ingreso y del poder, enajenación cultural, depredación ecológica y extrema dependencia externa. Por el contrario, una sociedad que tienda a compatibilizar las metas relacionadas con el crecimiento económico a mediano y largo plazo, así como éstas con aquellas otras vinculadas a las restantes dimensiones anteriormente mencionadas, tenderá a presentar también un mayor grado de desarrollo social y distribución del ingreso, un elevado nivel de participación política, una clara conciencia de identidad cultural, una.mayor racionalidad en cuanto a la sustentabilidad ecológica del proceso y un mayor grado de autonomía nacional en lo que se refiere a su: estrategia de inserción externa.

En tal sentido, aparecería que una estrategia de participación activa, controlada o selectiva en el sistema internacional sería la más: funcional o favorable a la elección de opciones compatibles con la preservación de los intereses específicos de una sociedad frente a cada una de las dimensiones ąnteriormente señaladas.

Analizando las consecuencias que podrían tener las diversas opciones susceptibles de ser adoptadas por los países en desarrollo desde el punto de vista de su estrategia externa sobre sus estilos internos de desarrollo es posible sugerir también la existencia de cuatro alter. nativas. Para ello se utilizará el concepto de los costos y beneficios derivados de la participación de esos países en el sistema transnacio-

'Ver Informe Global preparado para el seminario sobre Estilos de Desarrollo y Medio Ambiente en América Latina, al cual se referf́a la nota al pie que figura al comienzo de este artículo. A su vez, estas dimensiones constituyen una elaboración y expansión, a un nivel extremadamente tentativo, de ideas contenidas en una Nota de Trabajo sobre Estilos de Desarrollo, preparadas por Anibal Pinto en 1978. 
nal, partiendo de la idea de que esa participación envuelve al mismo tiempo riesgos y oportunidades, como se señalaba más arriba. Estas alternativas serían las siguientes: I) aceptación de los costos y búsqueda de los beneficios; 2) aceptación de los costos sin búsqueda de los beneficios; 3) rechazo de los costos y búsqueda de los beneficios, y 4) rechazo de los costos sin búsqueda de los beneficios.

Ciertamente es posible imaginar diversas formas de regulación de los costos inducidos en los estilos de desarrollo de esos países por su integración en el sistema transnacional, intermedias entre su aceptación irrestricta o su rechazo. Lo que se quiere sugerir aquí es, simplemente, que sería difícil buscar los beneficios que podrían derivarse de una nueva división internacional del trabajo entre los países industrializados y los países en desarrollo sin que estos últimos incurran en algunos costos. La necesidad de regularlos, por su parte, se plantea precisamente en la medida en que los trate como costos y se reconozca que en ciertas circunstancias pueden anular los beneficios derivados de la adopción de las nuevas formas de participación en el sistema.

En suma, pues, las características que presente el estilo de desarrollo de un país dependerán fundamentalmente de la forma que adopten sus relaciones económicas externas $y$, muy particularmente, de la medida en que el estado sea capaz de intervenir en esas relaciones con el objeto de implementar una estrategia de participación selectiva en el sistema internacional que le permita lograr un balance entre los costos y los beneficios derivados de su relacionamiento externo, que sea compatible con sus intereses.

\section{REFERENCIAS}

B. Batassa, Export Incentiyes and Export Performance in Developing Countries: A Comparative Analysis, 1977.

C. F. Bergsten y L. B. Krause (editores), World Politics and International Economics, 1975.

S. Brown, New Forces in World Politics, 1974.

L. BROWN, World Withouth Boarders, 1972.
CEPAI, El Desarrollo Económico en América Latina y Algunos de sus Principales Problemas, 1949.

CEPAL, El Desarrollo Económico y Social y las Relaciones Externas de América Latina, 1979.

J. Chesshire y Keith Pavitt, Some Energy Futures, en World Futures: The Grate Debate, por G. Freeman y M. Jahoda.

Ph. Connelly y R. Perman, The Politics of Scarcity: Resources Con- 
flict in International Relations, 1975.

R. COOPER, The Economic of Interdependence, 1968.

R. COOPER, Economic Interdependence and Foreing Policies in the Societies, en World Politics, vol. 24, No 2, 1972.

J. DARMSTADTER, Energy in the World Economy, 1971.

P. Davmson, The Economics of Natural Resources, en Challenge, marzoabril de 1979.

C. Díaz-Alejandro, Las Relaciones Norte-Sur: EI Componente Económico, en Estudios Internacionales, NNo 37, enero 1977.

J. B. Donges, et al.; EI Orden Económico Mundial en la Encrucijada, en Donge, et al., América Latina y la Economía Mundial, 1979.

R."Dumont, Utopia or Else..., 1974.

P. T. Ellsworth, The Terms of Trade between Primary Producing and Industrial Gountries, en Interamerican Economic Affairs, Vol. X., Verano de 1956.

B. Evers, et al., Perspectives on Industrial Adjustment: The EEC and the Developing Countries, 197,7.

A. Fishlow, et al., Rich and Poor Countries in the World Economy, 1978.

M. J. Flanders, Prebisch on Proteccionism: An Evaluation, en Economic Journal, junio de 1964.

Chr. Freeman y M. Jahoda, World Futures: The Grate Debate, 1978.

J. K. Galbratth, The Nety Industrial State, 1967.
G. Germani, Politica y Sociedad en una Epoca de Transición, I962.

N. GonzÁlez, Prioridades de América Latina en el Diálogo Norte-Sur, en Estudios Internacionales, No 47, julio de 1979.

S. Griffith-Jones, Ẽ Crecimiento de la Banca Multinacional, los Mercados de Euromonedas y los Países de Ia Periferia, en Estudios Internacionales, No 44, octubre-diciembre 1978.

J. GRUnwald, El Comercio Intraindustrial Norte-Sur: Compartir la Producción Industrial entre los Países en Desarrollo y Desarrollados, en Estudios Internacionales, No 48, octubre de 1979.

E. HAGEN, On the Theory of Social Change, 1962.

R. HANSEN, Beyond the North-South Statemate, 1979.

G. Harbeler, Los Términos del Intercambio y el Desarrollo Económico, en H. S. Ellis (editor), El Desarro1lo Económico y América Latina, 1969.

A. Herrera, Catastrophe or New Society, 1976.

F. HILx y L. Tomassint (editores). América Latina y el Nuevo Orden Económico Internacional, 1979.

E. V. Iglesias, Informe del Secretario Ejecutivo al xirir Período de Sesiones de la GePAI, 1979.

Iivstitute of Sogial SGiences (La Haya), Conference on Adjustment Policies (Proceedings), 1977.

INTERNATIONAL BANK FOR RECONSTRUG. TION AN DEVELOPMEN, World Development Report, 1979. 
H. Jaguaribe, Implicaciones Polfticas del Desarrollo Latinoamericano, en Polftica Económica en Centro y Periferia, por C. Díaz-Alejandro, $\mathrm{S}$. Teitel y V. Tokman (editores).

P. J. Katzenstein, Between Power and Plenty: Foreign Economic Policies of the Advances Countries, 1978.

R. O. Krohane y J. S. NyE, Transnational Relations and World Polities, 1970 y $197 \mathrm{I}$.

R. O. Keomane y J. S. Nye, Power and Interdependence: World Politics in Transition, 1977.

H. KAHN, et al., The Next 200 Years, 1976.

H. Karen, World Economic Development: 1979 and Beyond, 1979.

Ch. Kindleberger, American Business Abroad, 1969.

S. Krasner, Oil is the Exception, en Foreign Policy.

S. Krasner, Defending the National Interest, 1974.

H. Malmgren, Trade Policies and Developing Countries in the Next Decade, en The North-South Debate, por J. Bhagwati (editor).

M. M. Molauglin, et al., The United States and World Development: Agenda for Action, 1979.

D. MaGlelland, The Achieving Society, 1961.

D. H. MeAdows, et al., The Limits to Growth, 1972.

M. Mesarovic y E. Pester, Mankind at the Turning Point, 1974.
E. J. Mishan, The Economic Growith Debate: An Assessment, 1977.

E. J. Mrshan, Technology and Growth, The Price We Pay, I971.

R. E. MÜLreR, Global Reach: The Power of the Multinational Corporations, 1974 .

R. E. MüLLER, Crecimiento Económico Nacional y Política de Estabilización en la Epoça de las Corporaciones Multinacionales, en Estados Unidos: Perspectiva Latinoamericana, $2 \%$ semestre en 1977 y rv Semestre de 1978.

D. Novic, A. World of Scarcities, 1976.

V. H. OpPenheim, The Past, We Pushed. Them, en Foreign Policy, No $25,1977$.

T. Parsons y E. ShILs, Totwards General Theory of Action, 1952.

I. B. PeArson, Partners in Development, 1969.

P. Peterson, U. S. Foreign Assistance in the 1979's: A New Approach, 1970.

A. Pinto; Concentración del Progreso Técnico y de sus Frutos en el Desarrollo Latinoamericano, 1965.

R. Prebisch, Problemas Téoricos y Prácticos del Crecimiento Económico, 1952.

R. PrebisGH, Transformación y Desarrollo: La Gran Tarea de América Latina, 1970.

D. RIESMAN, et al., The Lonely Crowd, 1951. 
N. Rockefeller, The Quality of Life in the Americas, 1969.

P. Rosenstein Rodin, Notes on the Theory of the "Big Push", 1961.

W. W. Rostow, The Stages of Economic Growth, 1960.

J. SEWELr, El Crecimiento del Norte ¿Es posible sin el Crecimiento del Sur?, en Estudios Internacionales No 42, abril de 1978 .

I. AdELman Spero, The Politics of International Economic Relations, 1977.

O. SUNKel, Capitalismo Transnacional y Desintegración Nacional en América Latina, en Estudios Internacionales, No 16, enero de 1971.

O. Sunkel, y E. Fuenzarida, Integración Transnacional y Desarrollo Na- cional, en Estudios Internacionales, No 44, octubre de 1978.

I'He Ecologist, A Blueprint for Survival, 1972.

L. Tomassini, La Grisis Energética Cinco Años Después, en Estudios Sociales, No 18, 1978.

L. Tomassini, Los Países de Desarrollo Intermedio en el Sistema Internacional: Una Visión desde América Latina, en Comercio Exterior, México, marzo de 1979.

J. Villanueva, Perspectivas del Desarrollo Industrial Latinoamericano, Una Compleja Transformación, 1978.

B. WArD, Only One Earth, 1973.

K. D. Wirson, Prospect for Growth, 1977. 